\title{
Preliminary Risk Assessment of the Integral Inherently-Safe Light Water Reactor
}

\author{
Kellen R. McCarroll, John C. Lee, Annalisa Manera \\ University of Michigan \\ Matthew J. Memmott \\ Brigham Young University \\ Paolo Ferroni \\ Westinghouse Electric Company
}

\begin{abstract}
The Integral, Inherently Safe Light Water Reactor (I²S-LWR) concept seeks to significantly increase nuclear power plant safety. The project implements a safety-by-design philosophy, eliminating several initiating events and providing novel, passive safety systems at the conceptual phase. Pursuit of unparalleled safety employs an integrated development process linking design with deterministic and probabilistic safety analyses. Unique aspects of the $\mathrm{I}^{2} \mathrm{~S}-$ LWR concept and design process present challenges to the probabilistic risk assessment (PRA), particularly regarding overall flexibility, auditability and resolution of results. Useful approaches to initiating events and conditional failures are presented. To exemplify the risk-informed design process using PRA, a trade-off study of two safety system configurations is presented. Although further optimization is required, preliminary results indicate that the $\mathrm{I}^{2} \mathrm{~S}-\mathrm{LWR}$ can achieve a core damage frequency (CDF) from internal events less than $1.01 \times 10^{-8} /$ ry, including reactor vessel ruptures. Containment bypass frequency due to primary heat exchanger rupture is found to be comparable to nonvessel rupture CDF.
\end{abstract}

\section{Keywords}

Integral reactor; PRA; initiating event; conditional probability; plant damage frequency

\section{Introduction}

The Integral Inherently-Safe Light Water Reactor (I2S-LWR) aims to set a new standard for nuclear power plant safety while maintaining the economic advantages of large, gigawatt-scale plants. Achieving this standard begins with a conceptual design that eliminates multiple accident scenarios and reduces the risk of others. However, development of the I'2S-LWR concept's complement of passive, highly reliable safety features continues to elevate these standards by integrating deterministic and probabilistic safety analyses.

\subsection{Safety Philosophy}

The I ${ }^{2} S-L W R$ concept's focus on safety is driven by three primary objectives:

1. Eliminate initiating events where possible; minimize risk otherwise

2. Maximize passivity in safety systems

3. Balance redundancy, diversity, and simplicity of safety systems
From the initial proposal, the $\mathrm{I}^{2} \mathrm{~S}$-LWR concept eliminated several key design basis accidents (DBAs), including large-break (LB) and medium-break (MB) loss of coolant accidents (LOCAs), seal LOCAs, and rod ejections via an integral reactor pressure vessel (RPV) [Pet12]. Where initiating events (IEs) were not eliminated, many were reduced in frequency. For example, by utilizing high-pressure secondary loops and micro-channel heat exchangers (MCHXs) instead of traditional steam generators, the probability of accidents similar to steam-generator tube ruptures (SGTRs) is reduced [Pet12]. Similarly, minimizing the number of RPV penetrations reduces small-break (SB) LOCA frequency. Additionally, the I ${ }^{2} S-L W R$ concept's large coolant inventory buffers the risk of many accident classes, as do the concept's highly passive safety systems. Even the static containment vessel is designed to slow SBLOCA break flow rates and eventually return condensate back to the RPV.

Design of reliable safety systems for $\mathrm{I}^{2} \mathrm{~S}-\mathrm{LWR}$ focuses on maximizing passivity. This approach has been shown to reduce overall plant risk in several instances [Wel14]. Table 1 illustrates the International Atomic Energy Agency's definitions of degrees of 
passivity in water-cooled plants. Level C passivity, the lowest level acceptable for many I2S-LWR safety systems, may utilize moving parts, but not stored operating power or an external activation signal. By relying on natural phenomena, high probability failure modes such as losses of electrical power and operator error are minimized or eliminated altogether. The $\mathrm{I}^{2} \mathrm{~S}-$ LWR concept is being developed to utilize natural circulation loops, gravity, and air as an ultimate heat sink wherever possible. Valves are designed to fail to a safe line-up without an applied motive force. Where motive forces are required, highly reliable sources of stored energy are used, either with safety-grade batteries, pressurized tanks or accumulators, compressed springs, or gravitational potential energy. However, few mechanical components will require longterm motive forces to operate. Additionally, a relatively small, hydraulically-coupled containment structure facilitates rapid, fully passive pressure equalization, slowing and eventually stopping LOCA break flows.

Table 1: Categories of passive safety systems [IAE91].

\begin{tabular}{l|cccc}
\cline { 2 - 5 } \multicolumn{1}{c|}{} & \multicolumn{4}{c}{ Class } \\
Passive System Elements & A & B & C & D \\
\hline Structures & x & x & x & x \\
Working Fluids & & x & x & x \\
Moving Mechanisms & & & $\mathrm{x}$ & $\mathrm{x}$ \\
Stored Operating Power & & & & $\mathrm{x}$ \\
External Activation Signals & & & & $\mathrm{x}$ \\
\hline
\end{tabular}

Degree of Passivity

Finally, high levels of safety require a balance of redundancy, diversity, and simplicity amongst safety systems. Redundancy is essential to satisfy the General Design Criteria of 10 CFR 50 Appendix A, ensuring that a single component or system failure does not cause severe consequences [AEC71]. However, deployment of many identical components or systems leaves the plant vulnerable to common cause failures (CCFs). Therefore, diversity of safety systems with similar objectives but fundamentally different strategies is essential. Still, numerous diverse safety systems, each with a large degree of redundancy, can be counterproductive from a safety (and economic) standpoint. In this case, the number of unexpected, complex system interactions can become overly burdensome on operators during unforeseen accident scenarios [Per84]. Therefore, a risk-informed design process assuring low-levels of risk without unnecessary complexity is required.

The balancing of redundancy, diversity, and simplicity whilst maximizing passivity and eliminating accident initiators presents an organizational challenge to the I'S-LWR safety team.

\subsection{Preliminary Probabilistic Risk Assessment}

Although the conceptual design sets the stage for achievement of unprecedented nuclear safety, the $I^{2} S$ LWR safety team is organized to execute and improve the concept's inherent safety. The I²S-LWR Preliminary Probabilistic Risk Assessment (PRA) is integrated with several other efforts in plant design and development. Hence, a brief overview of safety-team dynamics and common safety approach is given.

\subsubsection{Safety Team Organization}

For I2S-LWR development with three primary objectives, ensuring comprehensive safety requires a cooperative, iterative design approach from several working groups. Figure 1 diagrams this integrated process.

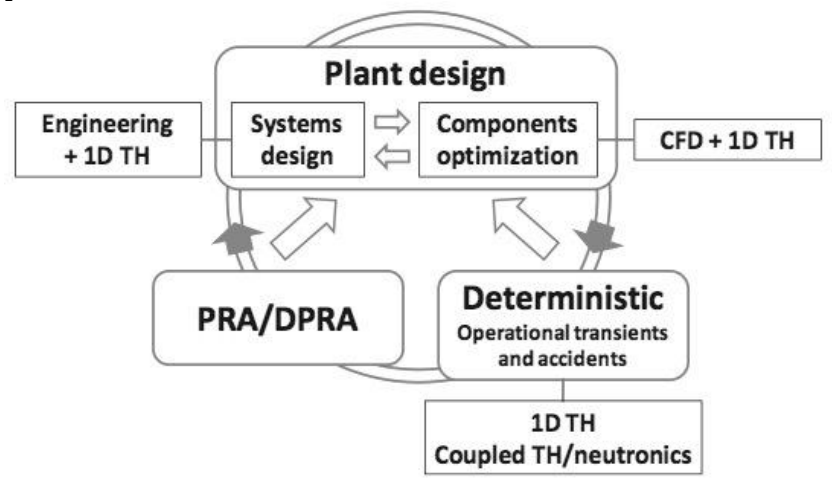

Figure 1: Safety-design team interactions [Pet12].

To initiate this scheme, a conceptual design was created specifying high-level system and component designs based on engineering judgment, 1-D thermalhydraulic (TH) analyses, and safety, economic, and performance goals [Pet12]. With a concept proposed, a list of anticipated limiting transient events (LTEs) was generated based on the U.S. Nuclear Regulatory Commission (NRC) Standard Review Plan (SRP) for consideration in both deterministic and probabilistic safety analyses [NRC07a]. Deterministic analyses of accident transients using coupled TH-neutronic codes give direct feedback for design parameters, as well as suggested success criteria and accident progression information for the PRA. The PRA, which will eventually evolve into a dynamic PRA (DPRA), identifies risksignificant design and operational factors, suggesting critical design modifications and deterministic analyses. This iterative process continues, ensuring the $\mathrm{I}^{2} \mathrm{~S}$-LWR concept evolves to meet its three primary objectives. 


\subsubsection{Preliminary PRA Purposes}

To support the advancing I ${ }^{2} S$-LWR design in parallel with deterministic safety analyses, the PRA team is developing a Level-1 Preliminary PRA focused on internal IEs. Traditionally, PRAs are performed after a plant is built (Generation II) or as part of the initial licensing process (Generation III+) [Miz02]. However, preliminary PRAs such as those of the I ${ }^{2} S$-LWR concept and its predecessor, IRIS, are performed alongside the design of the plant itself [Miz02]. Integrated, simultaneous development of the $\mathrm{I}^{2} \mathrm{~S}$-LWR concept with its associated risk assessment minimizes costly redesigns and maximizes safety. Section 1.2.1 discussed this iterative process amongst systems design, deterministic safety analyses, and PRA. One significant challenge of a Preliminary PRA is the large number of requisite assumptions since many "blanks" exist in the preliminary designs. However, despite many unknowns and significant uncertainty, simultaneous PRA and design development can obtain six vital objectives:

1. Evaluate design alternatives from a risk perspective

2. Illuminate safety systems in need of improvement, augmentation, or elimination
3. Evaluate testing and maintenance strategies

4. Support reduction of regulatory burdens

5. Suggest critical deterministic analyses

6. Estimate overall plant risk

\subsubsection{Safety System Requirements \& Considerations}

The ultimate goal of nuclear power plant safety is prevention of radioactive release to the environment. To ensure all necessary safety functions are performed by engineered safety features (ESFs), a master logic diagram inspired by the NRC's PRA Procedures Guide is provided in Figure 2 [NRC83]. Two of these events, corrosion and thermal stresses, are not managed directly by ESFs, but are of high operational importance. The remaining categories possess large degrees of interdependence. For example, insufficient reactivity control may lead to excessive RCS pressure, in turn leading to SBLOCA and possibly insufficient inventory control. This, then, may cause excessive containment pressures and temperatures. Despite the interdependence, however, safety functions are classified into the following five categories for convenience:

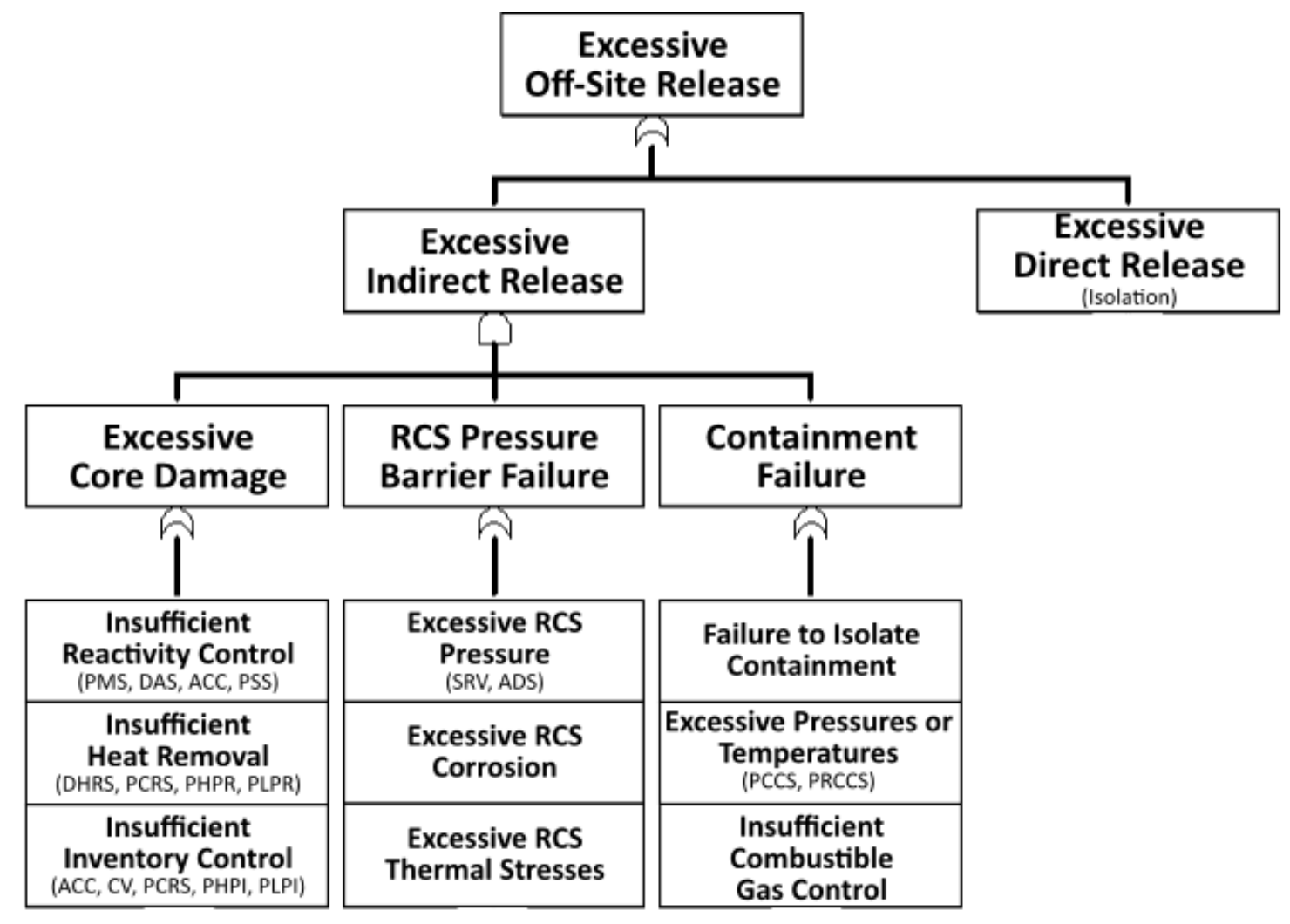

Figure 2: Master logic diagram for events leading to excessive off-site release. Specific safety systems referenced are formally introduced in Section 2. 
1. Reactivity Control - Excessive core heat generation must be prevented, both locally and globally, to prevent fuel failure. Therefore, termination of the fission chain reaction by negative reactivity insertion is a fundamental concern in most accident sequences. This may occur by purely physical properties such as Doppler broadening or channel boiling, although these may correspond to insufficient margins to core damage. Therefore, control rod insertions and increases in soluble boron concentration are currently preferable, though less passive options.

2. Decay Heat Removal - Fuel damage can occur in a shutdown, subcritical reactor due to decay heat generation. Decay heat removal options include heat exchangers inside or outside the RPV, through the RPV walls, or even by venting pressurizer steam while adding makeup water.

3. Inventory Control - Accidents involving losses of RCS inventory, such as SBLOCAs, threaten effective decay heat removal. Insufficient coolant inventory corresponds to low-pressures and/or critical heat flux (CHF). Injection can occur passively from pressurized tanks, accumulators, or gravity drains, and actively from high-head pumps in the chemical and volume control system (CVCS). Inventory control also requires termination or reversal of RCS break flows. In fact, equalization of RCS and containment pressures eliminates the motive force for a break flow, after which condensation inside the RPV can reverse break flow.

4. RCS Overpressure Control - Pressurization beyond RCS design pressure may rupture connecting piping, heat exchanger tubes and channels, or even the RPV itself, leading to a spectrum of SBLOCAs, interfacing system LOCAs (ISLOCAs), or vessel rupture. Although normal RCS overpressure protection is provided during normal operations by pressurizer spray, backup protection is available from one or more safety relief valves (SRVs).

5. Containment Integrity - As the final barrier to radionuclide release, containment integrity is a paramount safety concern. Although the I ${ }^{2} S-L W R$ containment vessel is designed for relatively high pressures, containment pressurization requires control in certain accident transients. Heat exchangers can reject heat to air or water, as in isolation condensers. Containment spray could also be utilized to aid condensation of containment steam. Ventilation of steam through a sparger in a suppression pool can also condense RCS steam before release to containment. Additionally, should $\mathrm{I}^{2} \mathrm{~S}$-LWR utilize zircaloy cladding, hydrogen and other combustible gases may require control. Ultimately, steam can be removed from containment in an accident with effective decay heat removal and reverse break flow.

\subsubsection{Limiting Transient Events}

Postulated accident classes anticipated to challenge $\mathrm{I}^{2} \mathrm{~S}$-LWR and the five safety function categories most severely must be defined before developing appropriate ESFs. The following are the events selected by the team from the SRP [NRC07a] for use in the deterministic and probabilistic safety analyses mentioned in Section 1.2.1:

Undercooling Events

- Loss of forced circulation (LOFC)

- Loss of feedwater (LOFW)

- Main feedwater line break (MFLB)

- MCHX channel blockage (MCHXB)

- Station Blackout (SBO)

Reactivity Insertion Accidents

- Boron dilution (BD)

- Inadvertent rod withdrawal (RW)

- Rod drop (RD)

Overcooling Events

- $\quad$ Spurious DHRS actuation (SPDH)

- Main steam line break (MSLB)

Loss-of-Inventory Events

- Small-break LOCA (SBLOCA)

- Spurious ADS actuation (SPADS)

Containment Bypass Events

- DHRS heat exchanger tube rupture (DHTR)

- MCHX channel rupture (MCHXR)

Undercooling events involve loss of some portion of core heat removal capacity without an increase in core heat output during normal or shutdown conditions. Consequently, fuel and coolant temperatures increase, possibly leading to CHF and fuel damage. Increasing RCS temperatures also cause pressurizer in-surges, increased RCS pressure and possibly lifted SRVs. Undercooling LTEs include: loss of reactor coolant pumps (RCP), loss of feedwater flow, breaks in main feedwater lines, restrictions in flow through MCHXs, or loss of power to all pumps.

Reactivity insertions cause power transients and result from improper rod movements or boron dilutions. Although rod ejections have been eliminated by design by moving control rod drive mechanisms (CRDMs) inside the RPV, inadvertent single or group rod withdrawals are still plausible. On the other hand, rod drops reduce reactivity, yet they also disrupt neutron 
flux distribution and potentially increase peak power densities, increasing the likelihood of local fuel damage. Without intervention, TH-feedback may also cause large power overshoots. Boron dilution events are also possible through improper CVCS operation, and though not predicted to be severe, are included in the Preliminary PRA for completeness.

Overcooling events reduce core inlet temperature, which, because of the I'S-LWR concept's negative moderator temperature coefficient (MTC) of reactivity, increase reactivity, reactor power, and fuel temperatures. RCS overcooling events result from breaks in steam lines both before (where vapor exists only after a break) and after the I ${ }^{2}$ S-LWR flashing drums, and from spurious operation of the decay heat removal system (DHRS). Breaks inside containment also threaten containment integrity.

Loss-of-inventory accidents endanger both core and containment. The I'S-LWR concept, however, has eliminated both LBLOCAs and MBLOCAs by design and the ${ }^{2} S$-LWR containment is designed specifically to mitigate consequences of SBLOCAs. However, not only does a loss of inventory increase the potential for CHF in the core, it may add complications with natural circulation needed for decay heat removal. Thus, core damage is feasible, although unlikely given the $I^{2} S$-LWR concept's integral design. An unmitigated loss of inventory could also uncover portions of the core, causing core melting. Other than SBLOCAs, loss of inventory may occur through a designed pathway, such as the automatic depressurization system (ADS) or stuck open SRVs (SORVs).

Finally, the I2S-LWR concept includes 12 heat exchangers inside the RPV: 8 MCHXs and 4 decay heat removal heat exchangers (DHRHXs). Rupture of any one of these heat exchangers provides a direct pathway outside the containment structure, albeit in a closed loop in the case of the DHRHXs. Although these containment bypass events may have only small nuclear effects and cause no core damage, they represent a relatively direct means of defeating the defense-indepth barriers to atmospheric radionuclide release (see Figure 2). Therefore, $\mathrm{I}^{2} \mathrm{~S}$-LWR is equipped with isolation valves in each interfacing system to minimize the risk of containment bypass.

\section{$2 \quad I^{2} S$-LWR Engineered Safety Features}

With the preceding accident considerations and classifications, the working set of I ${ }^{2} \mathrm{~S}$-LWR ESFs is now defined. Figure 3 illustrates these ESFs and some of their operational flow paths, although valves are displayed in their normal, at-power positions. Note that only one of multiple trains of each system is displayed.

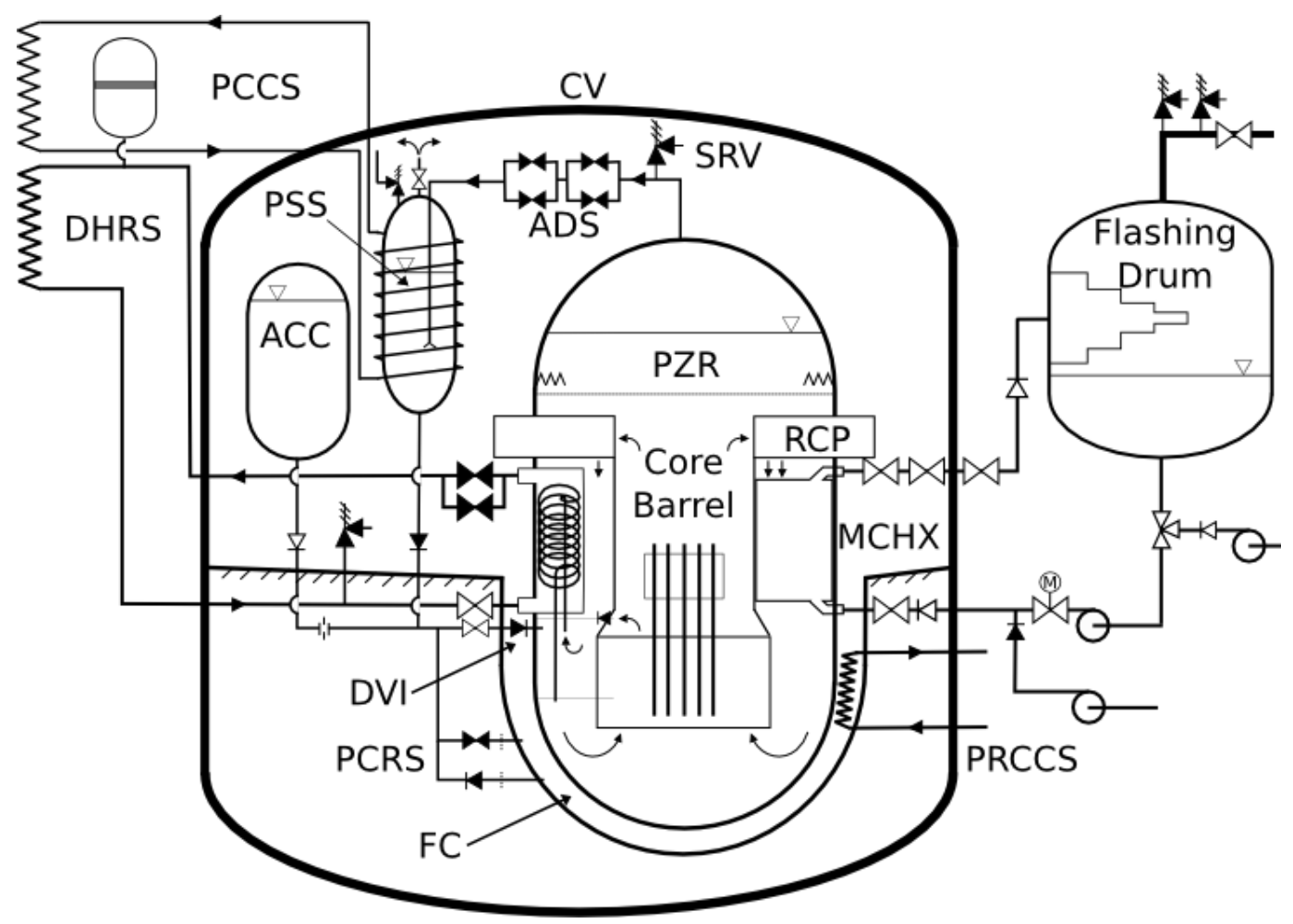

Figure 3: Preliminary schematic of single trains of key I²S-LWR safety systems. 


\section{Accumulators (ACC) - Inventory Control}

Two large, borated tanks pressurized by inert gas. Injection occurs passively via check valves on the direct vessel injection (DVI) lines when RCS pressure drops below ACC pressure. Borated water allows ACCs to increase reactivity margin in shutdown situations.

\section{Automatic Depressurization System (ADS) - RCS Overpressure Control \\ In some accident scenarios, it is desirable to} depressurize the RCS quickly to allow other ESFs to function. Therefore, I ${ }^{2} \mathrm{~S}$-LWR has two lines ultimately venting pressurizer (PZR) steam to containment via PSS, facilitating RCS depressurization. These lines also comprise part of the passive high-pressure injection/ recirculation (PHPI/R) "super-systems" and can be used for emergency pressure relief should SRVs fail to open.

\section{Decay Heat Removal System (DHRS) - Decay Heat} Removal

DHRS is a central I 2 S-LWR safety system, designed to remove decay heat indefinitely at full or partial RCS pressure by natural convection to the atmosphere via a dry cooling tower. Four separate trains, each with a DHRHX, pressurized secondary loop, and ultimate heat sink heat exchanger (UHSHX), provide high capability and reliability. Unlike other passive decay heat removal systems, DHRS has dedicated heat exchangers located inside the RPV, independent of the secondary system.

\section{Passive Containment Cooling System (PCCS) - Containment Integrity PCCS development is the subject of the following sections on Preliminary PRA development. In both cases, PCCS consists of two heat exchangers high in the containment volume to condense break steam. Each heat exchanger fosters natural convection to cooling towers, possibly shared with DHRS.}

\section{Passive Cavity Recirculation System (PCRS) - Inventory Control}

With RPV-containment pressure equilibrium and water level in the flood-up cavity (FC) above the DVI line and RCS level, sufficient gravity head exists to resupply the RPV with cavity water. The PCRS simply connects the FC to each DVI line with two parallel suction lines.

\section{Containment Vessel (CV) - Inventory Control}

By design, $\mathrm{I}^{2} \mathrm{~S}$-LWR establishes TH coupling in postulated SBLOCA situations to equalize RPV and containment pressure, eventually stopping break flows passively. The $\mathrm{CV}$ also incorporates a $\mathrm{FC}$ around the lower RPV head to collect water condensed by PCCS and subcooled by PRCCS for eventual recirculation via PCRS.
Passive High-Pressure Injection (PHPI) - Inventory Control

PHPI is a "super-system" consisting of ADS, PSS, and DVI lines. Each PSS vent is equipped with a normally-open isolation valve. To achieve PHPI, ADS is opened and the PSS vent valve is subsequently closed. PZR steam rapidly pressurizes the PSS tanks, and since these tanks are filled above normal PZR level, gravity drives PSS inventory into the RPV passively.

\section{Passive High-Pressure Recirculation (PHPR) - Decay Heat Removal}

PHPR is a unique "super-system" made possible if PCCS heat exchangers are integrated with the outer shells of the PSS tanks, as shown in Figure 3. PHPR initiates passively whenever PHPI is utilized. As PZR steam enters PSS tanks via ADS, PSS water temperatures rise conducting heat through the tank shell to PCCS secondary coolant. Thus, some PZR steam is condensed and returned to the RPV via DVI lines, providing additional passive decay heat removal.

\section{Passive Low-Pressure Injection (PLPI) - Inventory Control}

PLPI is a similar "super-system" to PHPI, except ADS is not required and the PSS vent valve must be open. Like PHPI, gravity-injection begins with pressure equilibrium between PSS and RPV. However, for PLPI, PSS is maintained at containment pressure via open vent valve. Thus, pressure equilibrium must also occur between RPV and containment.

\section{Passive Low-Pressure Recirculation (PLPR) - Decay Heat Removal \\ PLPR is the low-pressure analogue of PHPR. When containment is filled with steam, condensation inside PSS draws additional steam through the open vent and is cooled via PCCS. This internal condensate is directed through the DVI lines back to the RPV.}

\section{Passive Reactor Cavity Cooling System (PRCCS) - Containment Integrity}

The FC also contains two heat exchangers to maintain liquid water around the lower RPV and to further cool PCCS condensate before PCRS injection. The heat sink is tentatively assumed to be the cooling towers housing DHRS and PCCS heat exchangers.

\section{Pressure Suppression System (PSS) - Containment Integrity}

Two PSS trains primarily function to reduce steam enthalpy rejected to containment when depressurizing the RCS. ADS discharge is directed through a sparger into a suppression pool, condensing some steam before venting to containment. PSS also comprises part of the 
PHPI/R and PLPI/R "super-systems". PSS contents are assumed to contain soluble boron to allow PHPI to function as emergency boration tanks.

Several other common safety systems and components are included in the Preliminary PRA, but not modeled in depth. Reactivity control is primarily achieved via the protection and monitoring system (PMS) and its backup, non-safety diverse actuation system (DAS). RCS overpressure control is achieved by two primary SRVs sharing a single connection from the pressurizer with ADS branches.

Though several non-safety systems are capable of aiding accident mitigation, these are outside the scope of the current discussion and are not credited in PRA analyses. With these considerations, the question remains: how many systems does $I^{2} S$-LWR need for each safety function category? Balance is required, not just among redundancy, diversity, and simplicity, but also with economic and physical considerations. Working with the design team and deterministic analyses, the Preliminary PRA seeks to render I ${ }^{2}$ S-LWR safety systems reliable enough to minimize the number and complexity of additional systems. The remainder of this paper focuses on Preliminary PRA development.

\section{Preliminary PRA Development}

Development of the Preliminary PRA in parallel with plant design, along with the novel aspects of the $I^{2} S$-LWR conceptual design, presents challenges and opportunities in PRA approach and assumptions. These are detailed in Sections 3.1 and 3.2, respectively. An illustrative example of two key attributes of the ${ }^{2} \mathrm{~S}-\mathrm{LWR}$ Preliminary PRA follows in Section 3.3.

\subsection{Preliminary PRA Approach}

The current approach to the I ${ }^{2} S$-LWR Preliminary PRA stems from the goals of general preliminary PRAs, aspects of the I ${ }^{2} S$-LWR design, and the current scope of the probabilistic risk models.

\subsubsection{Requirements of a Preliminary PRA}

To support the risk-informed design approach, the following studies are employed:

1. Cut set analyses

2. Parametric studies

3. Sensitivity analyses

4. Trade-off studies
These studies, along with identification of dominant IEs, end states, and sequences, will identify key vulnerabilities in the $\mathrm{I}^{2} \mathrm{~S}$-LWR design, and in some circumstances, suggest improvements.

Unlike PRAs for operating plants, absolute values of core damage frequencies (CDFs) are de-emphasized in the Preliminary PRA because of the large uncertainties involved. In fact, absolute values are only utilized for comparisons with other plant designs and to inform the safety team whether additional safety systems are warranted.

More importantly, the Preliminary PRA must illustrate which components, systems, accident sequences, and accident initiators present the largest risks and require the design team's greatest attention. For this reason, little valuable information is gained from unnecessary conservatism in the Preliminary PRA; resolution and detail of minimal cut sets are sought vigorously, though never at the expense of conservatism in quantifiable damage frequencies.

The evolving nature of preliminary PRAs demands that risk models match the flexibility of the design itself. This is accomplished through large degrees of standardization regarding treatment of CCFs, fault tree and event tree structures, and documentation.

\subsubsection{Requirements from $I^{2} S$-LWR Conceptual Design}

Idiosyncrasies of the I ${ }^{2} S$-LWR concept present other challenges to the Preliminary PRA. First, since all ESFs are passive, many relatively large-probability failure mechanisms of analogous active systems are eliminated. As a result, focus shifts to rare failure mechanisms, some of which are traditionally excluded altogether under Supporting Requirement SY-A15 of [ASM09], which allows for omission of basic events accounting for less than $1 \%$ of a particular failure mode.

Second, the I' ${ }^{2} S$-LWR ESFs considered here are highly integrated. Single physical components often serve multiple safety functions and change state more than once during some accident sequences. System reliabilities may be affected by other systems' successes or failures. Therefore, care must be exercised in building the Preliminary PRA to accurately reflect the true states of components and systems in accident sequences; the Preliminary PRA itself must be highly integrated to reflect the physical nature of shared safety components.

\subsubsection{Preliminary PRA Scope}

Several other noteworthy aspects of the Preliminary PRA are affected by the scope of the individual tasks of traditional PRAs [Mai03]: 
1. Identify initiating event classes: All 14 LTEs listed in Section 1.2.4 are modeled.

2. Evaluate accident sequence progressions: Without extensive deterministic analyses, many assumptions regarding accident sequence progressions are required. Key assumptions are given in Table 2 of Section 3.2. Only safety-grade, passive systems are credited, except DAS and operator actions.

3. Determine success criteria of key safety systems: In the absence of extensive deterministic analyses, all system success criteria are conservatively assumed to permit only single train failures without system failure.

4. Develop accident event trees: Although the Preliminary PRA is primarily Level-1, only considering internal events, prudence allows for quantification of obvious containment failure sequences (e.g. SBLOCA without any containment or RCS heat removal). Thus, end states are delineated as such:

- $\mathrm{OK}$ - no fuel damage or release of radionuclides to the atmosphere

- $\quad$ CD - core damage occurs but radionuclides do not necessarily escape containment

- ECF - early containment failure occurs before appreciable heat can be removed

- LCF1 - late containment failure occurs, but core remains inside RPV

- $\quad$ LFC2 - late containment failure occurs and molten core is postulated outside RPV

- BYPASS - a direct pathway for radionuclides to escape containment exists and isolation fails.

With these end state definitions, our Preliminary PRA functions as a Level 1.5 PRA. Moreover, inclusion of the BYPASS end state complicates calculation of core damage frequency since these sequences do not imply any damage to fuel elements. BYPASS sequences contribute instead to containment bypass frequency (CBF). In anticipation of comparable CDF and CBF values [NRC90], we introduce the plant damage frequency (PDF) metric:

$$
\mathrm{PDF}=\mathrm{CDF}+\mathrm{CBF}
$$

However, team goals of CDF $<3 \times 10^{-7} /$ ry and large early release frequency (LERF) $<3 \times 10^{-8} /$ ry remain without a corresponding PDF target.
5. Develop system fault trees: As discussed in Section 2, I'2S-LWR is equipped with highly integrated ESFs, requiring fault tree (FT) modeling to be equally integrated. CCFs are modeled using a strict multiple-Greek letter (MGL) method with each common-cause basic event treated as an independent event [Mos90]. Additionally, many initiating events are modeled with FTs, including CCFs, allowing for incorporation of specific, component-level IEs into the FT logic of applicable ESFs. Several key instances of one system's failure probability conditioned by one or more separate system's success, failure, or even partial operation are modeled. Section 3.3 elaborates on both approaches.

6. Perform data analysis and human reliability analysis: Human reliability analysis (HRA) is outside the scope of the current Preliminary PRA. Instead, situations requiring operator action are assigned a failure probability of $1 \%$.

7. Quantify and interpret results: Recall that the Preliminary PRA serves the risk-informed design process. Therefore, results are used to evaluate design alternatives, focus deterministic analyses, and highlight vulnerabilities. Results are analyzed using minimal cut set information for accident sequences, event trees, or the entire PRA, using several importance measures, or even comparison of two alternate designs based on CDF, CBF, or PDF. When design changes are implemented, part or all of the preceding steps are iterated.

Although several iterations of the preceding process occurred to attain the current incarnation of the Preliminary PRA, namely DHRS and ADS developments, one illustrative trade-off example is chosen and motivated further in Section 4.1.

\subsection{Preliminary PRA Assumptions}

As noted in Section 1.2.2, assumptions are a necessary and prevalent aspect of a preliminary PRA. Table 2 collects key assumptions into three categories: 1) system functions and success criteria, 2) accident sequence progressions, and 3) quantification.

Reliability data is drawn extensively from [NRC07b], while MGL parameters are taken from [EPR90]. Instrumentation and control (I\&C) systems are modeled with single events with probabilities borrowed from Westinghouse's AP1000 Design Control Document [WEC03]. 
Table 2: Key PRA assumptions by category.

\begin{tabular}{|c|l|}
\hline$\#$ & Description \\
\hline $1-1$ & $\begin{array}{l}\text { Each accumulator and PSS tank contains sufficient } \\
\text { inventory to keep the core covered after a DVI line } \\
\text { break until CV-RPV pressure equilibrium is } \\
\text { achieved. }\end{array}$ \\
\hline $1-2$ & $\begin{array}{l}\text { Flow to } 3 \text { of } 4 \text { DHRS inlets, either over the core } \\
\text { barrel or through } \geq 3 \text { core barrel bypass valves, is } \\
\text { sufficient for long-term decay heat removal. }\end{array}$ \\
\hline $1-3$ & $\begin{array}{l}\text { 2 penetrations for I\&C cables are near the height } \\
\text { of the RCPs. }\end{array}$ \\
\hline $1-4$ & $\begin{array}{l}\text { One PCCS train is sufficient for long-term } \\
\text { containment integrity, except with } \geq 2 \text { MSLBs in- } \\
\text { containment, which requires both trains. }\end{array}$ \\
\hline $1-5$ & $\begin{array}{l}\text { PCRS success following DVI line ruptures requires } \\
\geq 1 \text { accumulator or PSS tank injection. }\end{array}$ \\
\hline $1-6$ & $\begin{array}{l}\text { DVI line breaks inside DVI check valves are viable } \\
\text { pathways for PCRS flow. }\end{array}$ \\
\hline $1-7$ & $\begin{array}{l}\text { A single PRCCS train maintains containment } \\
\text { integrity only with significant FC inventory. }\end{array}$ \\
\hline $2-1$ & $\begin{array}{l}\text { All ruptures of MCHXs and DHRHXs are detectable } \\
\text { and isolable; failure to isolate the appropriate } \\
\text { train(s) leads to BYPASS. }\end{array}$ \\
\hline $2-2$ & $\begin{array}{l}\text { Reactor trips cause turbine, main feed pump } \\
\text { (MFP) and RCP trips. SBO causes all of the above. }\end{array}$ \\
\hline $2-3$ & $\begin{array}{l}\text { Failure to relieve RCS overpressure situations } \\
\text { causes simultaneous rupture of both DVI lines. }\end{array}$ \\
\hline $2-4$ & $\begin{array}{l}\text { With no credit given to emergency boration } \\
\text { functions, core damage is conservatively assumed } \\
\text { to occur without any automatic or manual trips } \\
\text { (PMS, DAS, and scram breakers). }\end{array}$ \\
\hline $3-1$ & $\begin{array}{l}\text { Several unknown conditional probabilities are } \\
\text { conservatively estimated. }\end{array}$ \\
\hline $3-2$ & $\begin{array}{l}\text { Loss of primary flow due to non-condensable gas } \\
\text { binding (NCGB) of DHRHXs occurs at the same } \\
\text { hazard rate as plugging (6.45x10-7 /hr) [NRC07b]. }\end{array}$ \\
\hline $3-3$ & $\begin{array}{l}\text { MCHXs rupture at a hazard rate of 3.48x10-8/hr } \\
\text { [NRC07b]. }\end{array}$ \\
\hline
\end{tabular}

\subsection{Preliminary PRA Example: SBLOCA}

Before presenting results of the Preliminary PRA, we first present archetypal cases of several important aspects of the risk models that lead to such valuable insights. The SBLOCA/DVI line rupture example demonstrates our treatment of initiating events, partial system operation, and conditional probabilities.

SBLOCAs present a challenge to Preliminary PRA development since plant response depends heavily on the location of the rupturing vessel penetration. Specifically, breaks can occur at high (in the pressurizer), medium (near RCPs), or low (DVI lines) locations. No single, traditional ET was found satisfactory to model these differing behaviors, so a multi-path approach was taken. Figure 4 shows the first stage of the SBLOCA ET that delineates break locations. Although only low breaks (i.e. DVI line ruptures) are emphasized, each break location is modeled similarly.

In many cases, ETs begin with an analyst-supplied IE frequency, usually in units of "per reactor-year" (/ry) [NRC87], that multiplies each set of failure probabilities resulting in a plant damage end state frequency. Since the IE frequency supplied must include all specific IEs (e.g. SBLOCAs) but the ET must model the worst-case scenario for conservatism, the resolution of the resulting set of events is severely diminished. Moreover, this approach fails non-conservatively to distinguish common-cause initiating events. Although coincidental IEs involving relatively independent components such as DVI lines and MFPs may be reasonably neglected, simultaneous failures of similar components, such as ruptures of both DVI lines should not be discounted to maintain conservatism. By modeling specific IEs with FTs (IEFTs) embedded in ETs, peculiarities of sequence progressions unique to the specific IE can be modeled. Figure 5 demonstrates an IEFT structure, which links to the bottom branch of Figure 4 (sequence 12).

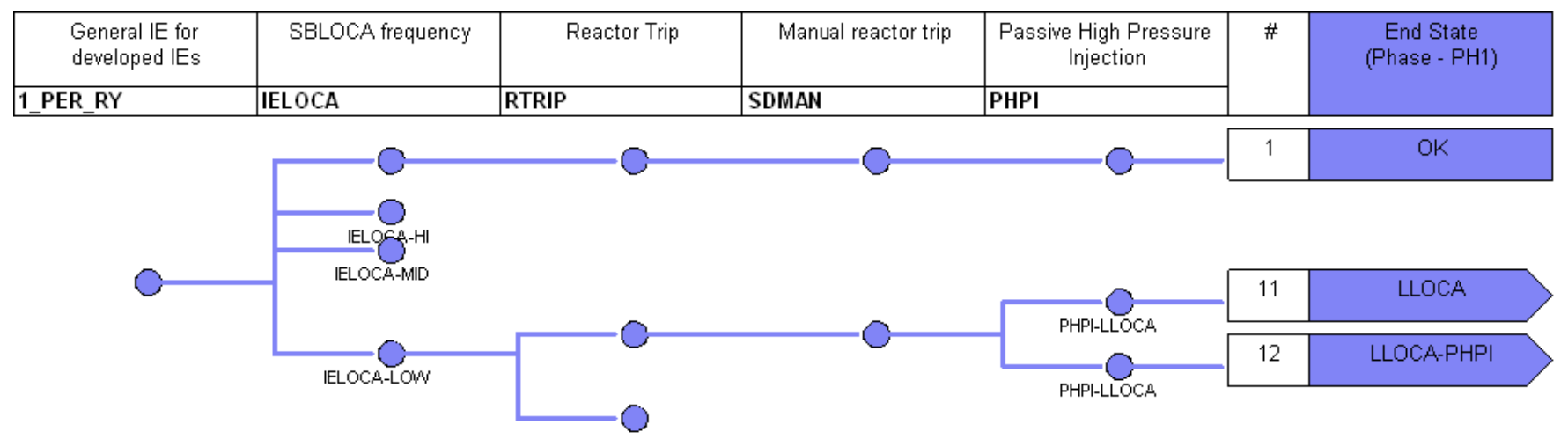

Figure 4: Truncated first-stage SBLOCA ET focusing on DVI line ruptures with successful reactor trips. Note that an IE frequency of $1 r^{-1} y^{-1}$ simply converts IEFTs to the appropriate units. 
Additionally, inclusion of specific, component-level IE information into ET sequences allows for tailored FT modeling. For example, the right-most branch point in Figure 4 calls on the "PHPI-LLOCA" FT, which specifically models the PHPI super-system for LowLOCAs (i.e. DVI line ruptures). Use of IEFTs, then, allows the PHPI-LLOCA FT to incorporate information regarding which DVI line ruptured through a "lock \& key" logic mechanism using basic events (see Figure 6).

Carrying the specific IE basic event through to system FT logic is of particular importance to integral designs such as I'2S-LWR. For example, if the A-train DVI line ruptures, then the B-train of PHPI is the only train still capable of success. Similarly, if this PHPI-B train succeeds, then the PCCS-B train must succeed for PHPR success, the ADS-B train valves must have opened, and so on (see Figure 3). By using the specific IE basic event as a "key" to the AND gate "lock," only the specific subsystem failures that match the specific IE are solved. Thus, IEFTs allow for simple treatment of partial system operation. Moreover, the resulting system FT logic is more directly transparent without referring to documented applicable initial conditions or programmed "flag sets" (described below) to set IEs to "TRUE" or "FALSE."
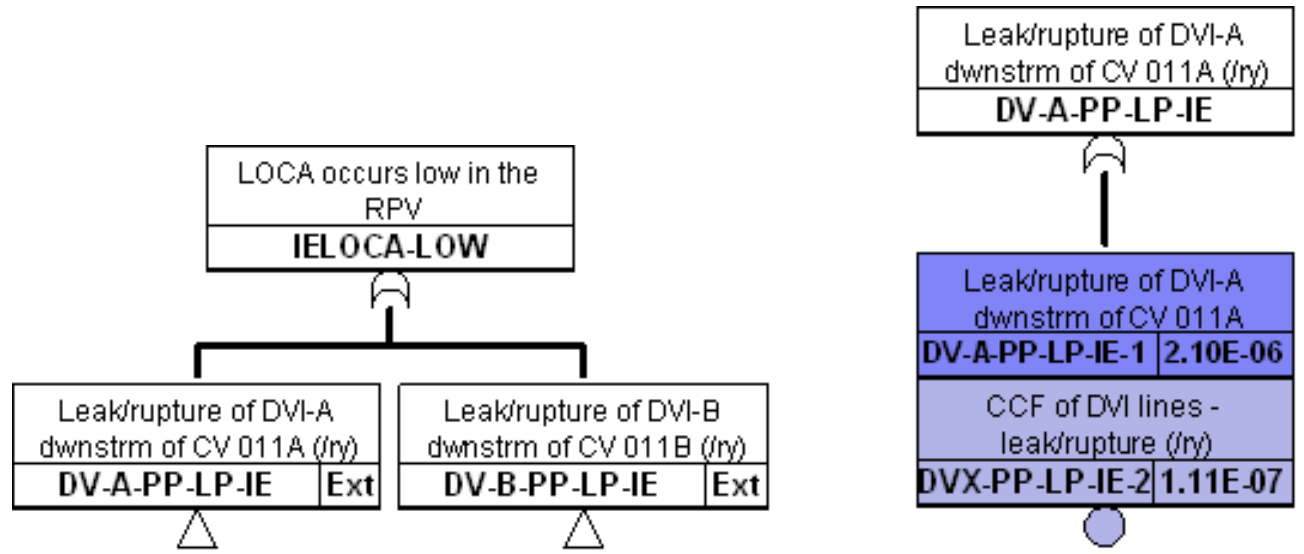

Figure 5: IEFT for DVI line ruptures (left). Each DVI line is broken into an independent rupture and a shared CCF (right), each of which is incorporated into appropriate system FTs such as Figure 6.



Figure 6: FT logic for PHPI following any DVI line rupture. Note the incorporation of IEs to "unlock" the appropriate train failure AND gate "lock." 


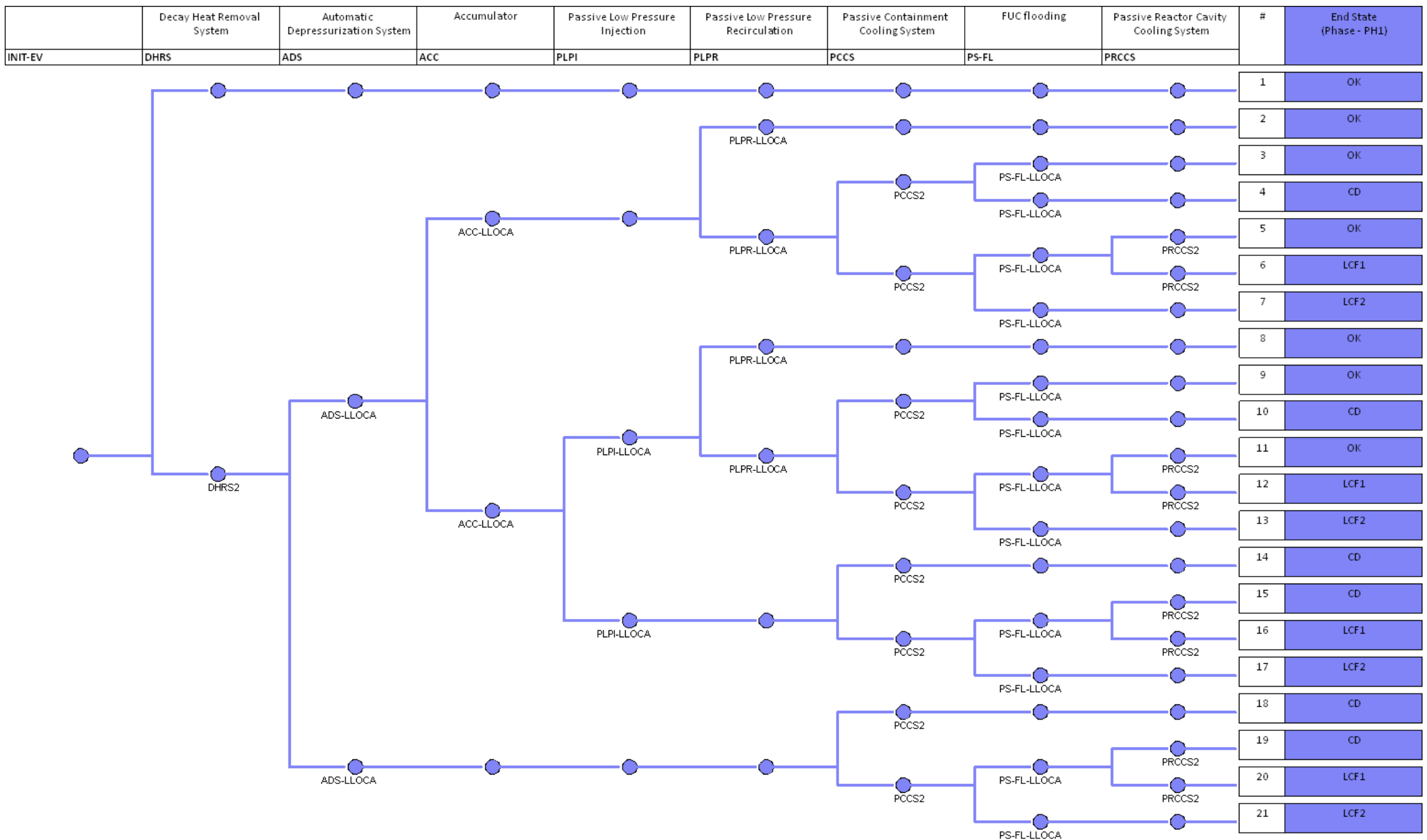

Figure 7: Transfer ET logic for a Low-LOCA (DVI line rupture), followed by reactor trip and PHPI failure (sequence 12 of Figure 4). Note that both PHPI and ACC injection affect DHRS failure probability by maintaining flow pathways over the core barrel (see Figure 9). 
To illustrate our technique for conditional probabilities, we continue the sequence for a DVI line rupture with PHPI failure (sequence 12 in Figure 4). This path takes us to another ET, given in Figure 7, displaying sequence logic for the remaining ESFs.

Although this ET is large, our present discussion focuses only on the first (DHRS) and third (ACC) branches of sequence 14. Early Preliminary PRA studies showed that DHRS could offer very reliable decay heat removal, partially because its primary inlet can take suction from two pathways, shown in Figure 3. Flow may rise from the core, spill over the core barrel, and travel downward around the MCHXs, or pass through a set of core barrel bypass check valves (see DHA-INLET$F L O$ gate of Figure 8). If one of these pathways (e.g. over the core barrel due to low RCS level) were to be eliminated, DHRS failure probability would increase markedly. In fact, it would be no lower than the failure probability of the check valves. Thus, DHRS reliability is strongly tied to successful inventory control.

In our ET example, we have established a priori that PHPI has failed before questioning DHRS success. However, ACC injection will likely begin after DHRS initiation, yet affect RCS level and therefore DHRS reliability. Figure 8 and Figure 9 demonstrate how both the a priori (PHPI) and posterior (ACC) ET information is incorporated into the DHRS FT logic.
Similar to using specific IE information to "key" affected system success criteria, RCS level conditioning during Low-LOCA/DVI line ruptures uses a common approach using house events as "keys" to AND gates to "unlock" appropriate FT logic [Smi11]. Normally set to FALSE, the house event is programmed via "flag set" to change to TRUE if either (or both) DVI lines rupture, thereby opening the RCS level logic for DVI line ruptures (Figure 9) to the DHRS FT logic (Figure 8). Similar house events "lock" FT logic for other events challenging RCS level. Thus, a single DHRS FT can be utilized for multiple IEs, increasing auditability. On the other hand, a programmed flag set is necessary here to prevent multiple IEs appearing in cut sets, reducing auditability.

Three inventory control combinations are considered for RCS level conditioning following LowLOCAs: successful PHPI (no relevant failures), PHPI failure (implied ACC success), and no injection (PHPI and ACC failures). Implanting these system FTs into the RCS level FT effectively "keys" the appropriate conditional probability and ensures mutual exclusivity.

Together, integration of IEFTs into system FTs and conditioning probabilities using either "key \& lock" strategy provide the I ${ }^{2} S-L W R$ Preliminary PRA with high-resolution minimal cut sets.



Figure 8: Truncated FT logic for a single DHRS train focusing on failures of primary flow paths. Note the RC-LEV-CB transfer gate to Figure 9. This gate applies to all DHRS trains and 


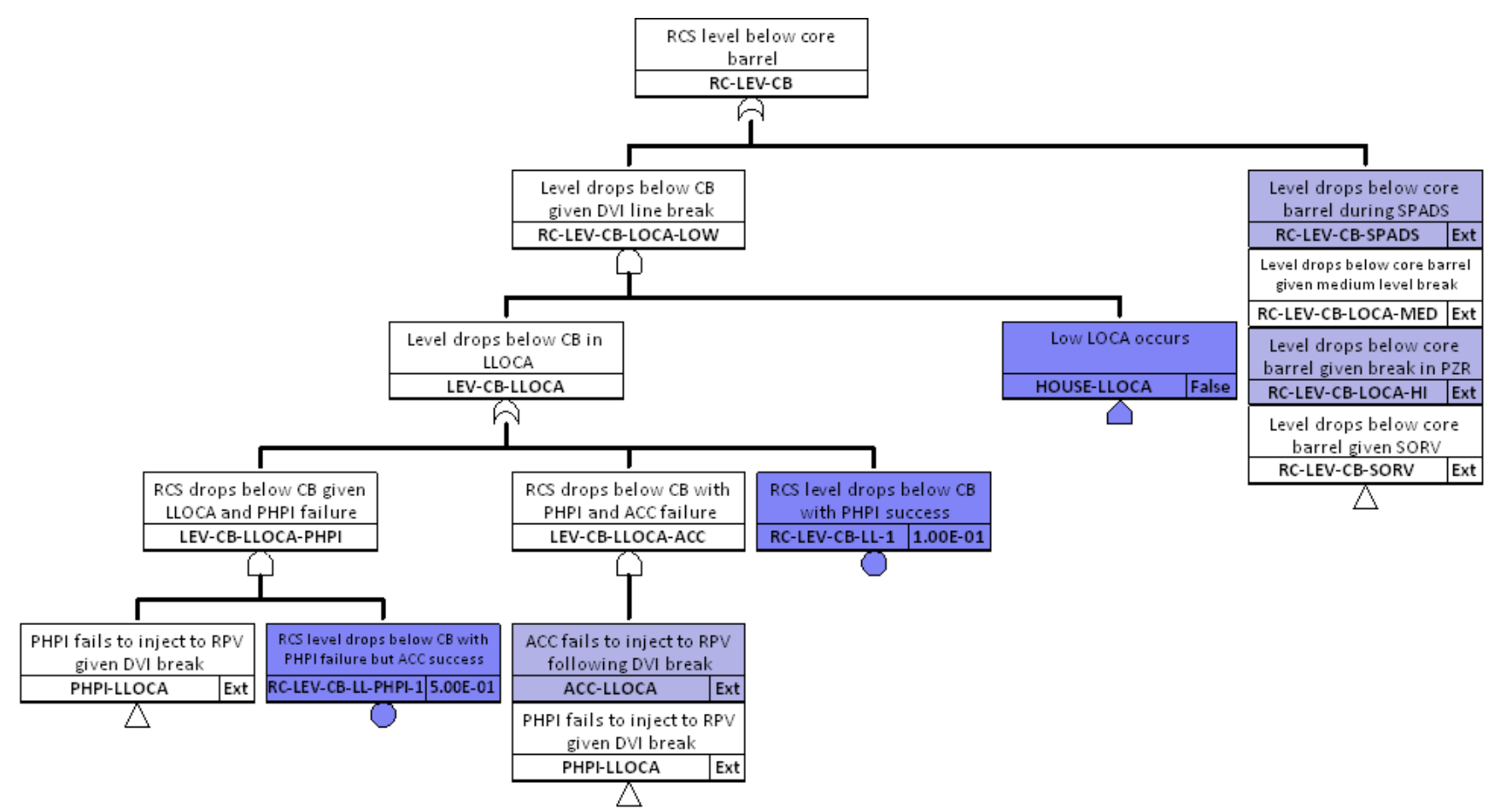

Figure 9: Compressed FT logic for RCS level drops relative to the top of the core barrel focusing on Low-LOCAs. The HOUSE-LLOCA event is set to TRUE for sequences involving DVI line ruptures, "unlocking" three logical possibilities for RCS level drops: 1) no injection failures (10\%), 2) PHPI failure, ACC success (50\%), and 3) ACC and PHPI injection failures (100\%). Other loss-of-inventory events (right) utilize similar FT modeling strategies.

\section{Risk-Informed Design: An Example}

The Preliminary PRA has already produced several examples of risk-informed design progress, including improvements to DHRS and ADS. Specifically, the early Preliminary PRA illuminated the need for the parallel set of isolation valves in the DHRS secondary loop, improving overall system reliability by two orders of magnitude. Preliminary PRA development of the ADS virtually eliminated the SPADS initiator from the overall risk profile. However, the following sections illuminate the risk-informed design process using a trade-off study involving PCCS design. Preliminary PRA results are presented at several levels and clearly motivate the development of the proposed design.

\subsection{Example Trade-Off Study: PCCS Design}

Two locations are proposed for the in-containment PCCS heat exchangers. Since PCCS is used extensively across many accident scenarios, this trade-off study demonstrates the depth of the current Preliminary PRA evolution, covering all 14 LTEs listed in Section 1.2.4.

The base case PCCS heat exchangers hang from the upper containment structure. Since containment steam will initially accumulate at the highest points, this location allows for maximum temperature differences between containment atmosphere and PCCS secondary working fluid early in loss of inventory events, initiating and driving the PCCS natural convection loop.

Alternatively, the PCCS heat exchangers are integrated around the exterior walls of the PSS tanks (see Figure 3). Although this arrangement must physically lower the PCCS heat exchangers somewhat, this location allows PCCS to serve multiple functions: both to condense containment steam and receive conducted heat from PSS inventory, creating the PHPR and PLPR functions described in Section 2. Neither of these diverse, passive means of decay heat removal requires additional equipment nor actuation signals. However, PSS tank ruptures might also destroy PCCS heat exchangers.

The integral PCCS-PSS design is expected to have several advantages other than overall CDF reduction. Although manufacturing such heat exchangers may present significant challenges, the arrangement is expected to reduce overall costs allowing for a more compact containment, reducing both construction costs and increasing CV design pressure. However, economics and PCCS performance are not the focus of the current trade-off study. 
The PCCS trade-off study clearly illustrates the utility of Preliminary PRA in making high-level design decisions. Results also exemplify insights gained from the Preliminary PRA that suggest future improvements and foci of deterministic analyses.

\subsection{Results, Analysis \& Updates}

Results are presented for two PCCS designs. Designs are compared using overall CDF/CBF/PDF and dominant accident initiator classes, accident sequences, cut sets, and single event importance measures. Finally, recommendation of the integral PCCS-PSS follows from Preliminary PRA insights.

\subsubsection{Damage Frequencies and Initiators}

Figure 10 and Figure 11 compare CDF, CBF, and PDF, excluding vessel rupture events, for each PCCS configuration, along with breakdowns by IE class. PDF estimations are well below CDF and LERF targets given in Section 3.1.3 for both designs, even with inclusion of vessel ruptures $\left(1.00 \times 10^{-8} /\right.$ ry $)$ [EPR90]. However, Figure 11 shows a $18 \%$ drop in PDF for the integral PCCS-PSS design resulting from a 30\% drop in CDF.

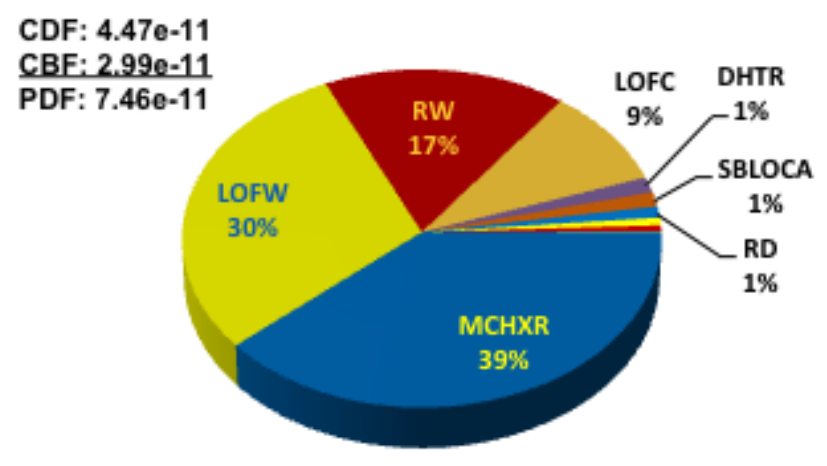

Figure 10: PDF distribution by IE for base case.

Interestingly, initiators such as LOFW, RW, LOFC, and SBO experience large drops in CDF contributions (27\%-99\%) due to the alternate means of decay heat removal offered by the integral PCCS-PSS design, yet SBLOCA contribution is dropped negligibly. Further analysis is required in subsequent sections to explain this phenomenon. However, significant drops in absolute CDF/PDF are strong motivators for adoption of the integral PCCS-PSS design.

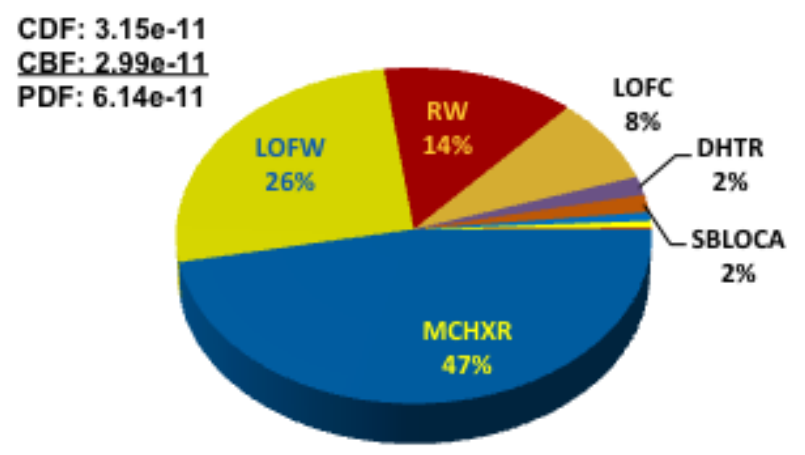

Figure 11: PDF distribution by IE for integral PCCS-PSS.

\subsubsection{Risk-Significant Sequences and Cut Sets}

Next, we examine the most risk-significant accident sequences and cut sets. Note that in the following discussion, the term sequence refers to a set of system failures and successes leading to an end state, whereas cut set refers to the set of individual component failures or phenomena leading to an end state. For I ${ }^{2} S$-LWR and its integral design, differentiating these two terms is imperative since a single component failure may cause multiple system failures. The safety team is particularly concerned with any such failure mechanism constituting a large portion of overall risk. Table 3 ranks the top 10 risk-significant sequences for the base case, hanging PCCS design, along with associated ranks for the integral PCCS-PSS design. Where applicable, Table 3 also lists significant minimal cut sets ( $>1 \% \mathrm{PDF}$ ). Note that a forward slash preceding ESF names designates system success. Underlined ESFs are unique to the integral PCCS-PSS design.

MCHXR-ISOLATION refers to isolation of the applicable secondary train(s) following MCHX rupture. RTRIP accounts for both automatic and manual scram via PMS and DAS, whereas SDMAN refers to manual shutdown via physical scram breakers. Note that in sequences 6 and 9, ADS appears twice. The first instance refers to operators utilizing ADS as an emergency pressure relief pathway within a short time window, whereas the subsequent usage refers to the standard depressurization function. 
Table 3: Top 10 accident sequences and associated risk-significant cut sets. Cut sets combine all combinations of failure events listed (e.g. MCHXR cut set \#6 combines probabilities of all 4 individual main steam train failures).

\begin{tabular}{|c|c|c|c|c|}
\hline $\begin{array}{c}\text { Base } \\
\text { (Integral) }\end{array}$ & Initiator & Sequence / Cut Set & $\begin{array}{l}\text { PDF } \\
\text { (\%) }\end{array}$ & $\Delta(\%)$ \\
\hline $1(1)$ & MCHXR & MCHXR-ISOLATION & 39 & - \\
\hline $1(1)$ & & $1 \mathrm{MCHX}$ rupture, I\&C fails to isolate, operator fails to isolate & 34 & - \\
\hline $6(6)$ & & $1 \mathrm{MCHX}$ rupture, mechanical failure of all MS valves to close & 2.5 & - \\
\hline $2(2)$ & LOFW & RTRIP, SDMAN, /SRV & 16 & - \\
\hline $4(4)$ & & $\begin{array}{l}1 \text { Class 1E DC fuse fails isolating single secondary plant train, failure of } \\
\text { PMS, DAS, and operator to scram }\end{array}$ & 4.5 & - \\
\hline $5(5)$ & & $\begin{array}{l}1 \text { Class } 1 E \text { DC bus fails isolating single secondary plant train, failure of } \\
\text { PMS, DAS, and operator to scram }\end{array}$ & 3.9 & - \\
\hline $7(7)$ & & $\begin{array}{l}2 \text { independent mechanical MFP failures, failure of PMS, DAS, and } \\
\text { operator to scram }\end{array}$ & 2.3 & - \\
\hline $11(9)$ & & $\begin{array}{l}\text { Inadvertent closing of MCHX outlet isolation air-operated valve, failure of } \\
\text { PMS, DAS, and operator to scram }\end{array}$ & 0.8 & \\
\hline $11(9)$ & & $\begin{array}{l}\text { Inadvertent closing of MCHX outlet isolation solenoid-operated valve, } \\
\text { failure of PMS, DAS, and operator to scram }\end{array}$ & 0.8 & \\
\hline $11(9)$ & & $\begin{array}{l}\text { Inadvertent closing of MCHX inlet isolation solenoid-operated valve, } \\
\text { failure of PMS, DAS, and operator to scram }\end{array}$ & 0.8 & \\
\hline $3(3)$ & RW & RTRIP, SDMAN, /SRV & 11 & - \\
\hline $2(2)$ & & RW, failure of PMS, DAS, and operator to scram & 11 & - \\
\hline $4(11)$ & LOFW & /RTRIP, /SRV, /SORV, DHRS, PHPR, /ADS, /PCCS, PLPR, PCRS & 8.3 & -97 \\
\hline $5(12)$ & RW & /RTRIP, DHRS, PHPR, /ADS, /PCCS, PLPR, PCRS & 5.9 & -97 \\
\hline $8(-)$ & & RW, CCF of all DHRHXs - plugging, CCF of all PCRS strainers - plugging & 1.5 & -100 \\
\hline $8(-)$ & & RW, CCF of all DHRHXs - NCGB, CCF of all PCRS strainers - plugging & 1.5 & -100 \\
\hline $6(4)$ & LOFW & /RTRIP, SRV, ADS, DHRS, /ADS, ACC, PLPI, /PCCS & 5.5 & - \\
\hline $7(5)$ & LOFC & RTRIP, SDMAN, /SRV & 4.9 & - \\
\hline $3(3)$ & & LOFC, failure of PMS, DAS, and operator to scram & 4.9 & - \\
\hline $8(16)$ & LOFC & /RTRIP, /SRV, /SORV, DHRS, PHPR, /ADS, /PCCS, PLPR, PCRS & 2.7 & -97 \\
\hline $9(6)$ & LOFC & /RTRIP, SRV, ADS, DHRS, /ADS, ACC, PLPI, /PCCS & 1.8 & - \\
\hline $10(7)$ & DHTR & DHRS secondary isolation, Atmospheric isolation & 1.5 & - \\
\hline $10(8)$ & & $\begin{array}{l}1 \mathrm{DHRHX} \text { rupture, isolation valve fails to close, relief valve fails to open, } \\
\text { UHSHX leaks }\end{array}$ & 1.0 & - \\
\hline $11(8)$ & SBLOCA & DVI line rupture(s), /RTRIP, PHPI, DHRS, /ADS, ACC, PLPI, /PCCS & 1.4 & - \\
\hline $12(9)$ & RD & RD, operator fails to adjust, failure of PMS, DAS, and operator to scram & 0.7 & - \\
\hline $14(10)$ & MCHXB & 2 or more MCHX blockages, failure of PMS, DAS, and operator to scram & 0.5 & - \\
\hline
\end{tabular}

Interestingly, the top 3 sequences in Table 3 are unaffected by changes in PCCS configuration. This behavior is easily explained in the unmitigated MCHXR and transients without scram since none call on decay heat removal before containment bypass or core damage occurs, respectively. However, as mentioned in Section 4.2.1, SBLOCAs do require decay heat removal and the addition of PHPR and PLPR were expected to reduce risk. However, comparison of the SBLOCA sequence contribution to PDF (1.4\%) in Table 3 and total SBLOCA contribution in Figure 10 reveals that nearly all risk presented by SBLOCAs involves a single sequence (sequence 12 in Figure 4, followed by sequence 14 in Figure 7). In fact, simultaneous, common cause rupture of both DVI lines between the RPV and DVI check valves accounts for all of the risk associated with this sequence (and the vast majority of SBLOCAs, in general). In this case, no injection or recirculation may 
occur from ACC or PSS tanks. Without any injection, RCS level is conservatively assumed to drop below the top of the core barrel (see Assumption 1-1 and Figure 9), eliminating one DHRS inlet flow path. Assumption 1-5 posited that DVI line ruptures are too severe for successful PCRS injection and cooling. Thus, DHRS is the only viable means of decay heat removal and its failure probability is increased markedly. Recall that neither insights regarding CCF IEs nor conditioning of DHRS failure probability would be illuminated without the techniques discussed in Section 3.3.

Also of note is the prominence of both MCHXR and LOFW for both designs. Although the top 3 sequences are unaffected by the addition of decay heat removal pathways, three top 10 sequences experience risk reductions of over $96 \%$. Three IEs are represented in this group, though each is followed by successful reactor scram. Therefore, decay heat removal becomes the focus for safe termination of the accident and the benefits of an additional, diverse means of decay heat removal are realized. Many other sequences with smaller individual risk significance benefit from additional decay heat removal pathways, producing the $30 \%$ reduction in CDF seen in Figure 11.

Although PCCS configuration has no direct effect on $\mathrm{CBF}$, an implicit connection exists since LOFWs are often initiated by spurious closing of the secondary isolation valves (cut sets ranked \#11) allocated to minimize CBF from MCHXRs. Thus, with recognition that an integral PCCS-PSS reduces CDF, further protection from MCHXRs was added with multiple, diverse isolation valves on both "main steam" (MS) and feedwater (FW) lines at the expense of LOFW frequency.

These Preliminary PRA insights beyond $\mathrm{CDF} / \mathrm{CBF} / \mathrm{PDF}$ numbers are invaluable to subsequent design decisions.

\subsubsection{Risk-Significant Failure Mechanisms}

Investigation of risk-significant components and phenomena focuses on two importance measures: Fussell-Vesely (FV) and risk increase ratio (RIR) to identify opportunities for further risk reduction and failure mechanisms whose occurrence would be particularly detrimental, respectively. Fussell-Vesely measures the fraction of total failure probability associated with a specific failure event [Lee11]. Table 4 compares the top 10 Fussell-Vesely failure mechanisms for each PCCS configuration.

For the base case, hanging PCCS design, common cause plugging of all $4 \mathrm{FC}$ strainers carries a large Fussell-Vesely importance rank (\#7). However, with the integral PCCS-PSS design, no cut set above the truncation level (of $10^{-17} / \mathrm{ry}$ ) is obtained. This is a result of decreased reliance on PCRS as a backup decay heat removal method upon introduction of PHPR and PLPR (see sequences 4, 5, and 8 in Table 3).

Table 4: Risk-significant Fussell-Vesely failure
mechanisms.

\begin{tabular}{|c|c|c|}
\hline Base & Failure Mechanism & Integral \\
\hline 1 & Rupture of MCHX - single & 1 \\
\hline 2 & $\begin{array}{c}\text { Automatic actuation of } \\
\text { secondary isolation valves }\end{array}$ & 2 \\
\hline 2 & $\begin{array}{c}\text { Manual actuation of } \\
\text { secondary isolation valves }\end{array}$ & 2 \\
\hline 4 & $\begin{array}{c}\text { Automatic and manual scram } \\
\text { via PMS }\end{array}$ & 4 \\
\hline 4 & $\begin{array}{c}\text { Automatic and manual scram } \\
\text { via DAS }\end{array}$ & 4 \\
\hline 4 & $\begin{array}{c}\text { Operator manually trips } \\
\text { scram breaker }\end{array}$ & 4 \\
\hline 7 & $\begin{array}{c}\text { CCF of all FC strainers - } \\
\text { plugging }\end{array}$ & - \\
\hline 8 & $\begin{array}{c}\text { Inadvertent rod withdrawal } \\
\text { Loss of forced circulation }\end{array}$ & 10 \\
\hline 9 & $\begin{array}{c}\text { Class 1E distribution panel } \\
\text { fuse fails - single }\end{array}$ & 11 \\
\hline 10 & $\begin{array}{c}\text { Manual RCS pressure relief } \\
\text { via ADS }\end{array}$ & 8 \\
\hline 13 & CCF of SRVs to open & 9 \\
\hline 16 &
\end{tabular}

Several themes are evident from the Fussell-Vesely rankings. First, reliable actuation of key safety functions, namely reactor scram and secondary isolation play a major role in overall risk. However, improvements to I\&C design are beyond the scope of the Preliminary PRA. Second, physical rupture of MCHXs is of considerable concern. Admittedly, little data is available on MCHX rupture frequency, and although these components are expected to be more robust than current steam generators, the current analysis conservatively assumes rupture frequencies comparable to current heat exchangers (see Assumption 3-3).

Unlike Fussell-Vesely, RIR indicates the increase in risk if the given component were sure to fail [Lee11]. Table 5 compares the top 10 RIR failure mechanisms for both configurations.

In general, the RIR ranks reflect events that are particularly rare, but would have strong effects on plant risk if they were to occur. Like the Fussell-Vesely rankings, actuation of safety functions ranks highly for RIR. Additionally, CCFs of DVI lines and DHRS rank highly. DVI line ruptures become especially important due to their detrimental effects on the PHPR and PLPR 
functions. Also note the increased relative importance of the Class 1E DC power supplies with the integral PCCSPSS design since ADS, which requires DC power, is required for PHPR.

Table 5: Risk-significant RIR failure mechanisms.

\begin{tabular}{|c|c|c|}
\hline Base & Failure Mechanism & Integral \\
\hline 1 & $\begin{array}{c}\text { Automatic actuation of } \\
\text { secondary isolation valves }\end{array}$ & 1 \\
\hline 2 & $\begin{array}{c}\text { CCF of 2 UHSHXs - rupture } \\
\text { CCF of 2 DHRHXs - NCGB }\end{array}$ & 3 \\
\hline 3 & CCF of 2 DHRHXs - plugging & 4 \\
\hline 5 & $\begin{array}{c}\text { CCF of 2 DHRS isolation } \\
\text { valves - spurious closing }\end{array}$ & 6 \\
\hline 6 & $\begin{array}{c}\text { CCF of both DVI lines - } \\
\text { rupture }\end{array}$ & 2 \\
\hline 7 & CCF of 3 DHRHXs - NCGB & 9 \\
\hline 7 & CCF of 3 DHRHXs - plugging & 9 \\
\hline 9 & CCF of 3 UHSHXs - rupture & 8 \\
\hline 10 & $\begin{array}{c}\text { CCF of 3 DHRS isolation } \\
\text { valves - spurious closing }\end{array}$ & 11 \\
\hline 17 & CCF of 3 Class 1E DC buses & 7 \\
\hline
\end{tabular}

\section{Summary}

Six specific tasks were cited for the Preliminary PRA in Section 1.2.2:

1. Evaluate design alternatives from a risk perspective The preceding analyses highlighted one example of the Preliminary PRA's ability to evaluate design alternatives. Specifically, the trade-off study examining two PCCS heat exchanger positions showed that the added decay heat removal function vastly outweighs the additional risk of PSS tank ruptures failing PCCS.

2. Illuminate safety systems in need of improvement, augmentation, or elimination Currently, I' ${ }^{2}$ S-LWR drastically outperforms its targets for both CDF and LERF, even with inclusion of the vessel rupture accident and containment bypass events. Although the Preliminary PRA is incomplete by nature, these results are encouraging considering the depth of the current PRA model and the omission of all active and non-safety systems. Therefore, additional safety systems are not recommended at this time. In fact, elimination of one or more ESFs could be evaluated.
3. Evaluate testing and maintenance strategies Although testing and maintenance strategies were not involved in the preceding discussion on PCCS design, this topic has been evaluated in previous Preliminary PRA work, particularly early DHRS development.

4. Support reduction of regulatory burdens Preliminary PRA-assisted development of PCCS and other systems suggests I ${ }^{2} S$-LWR safety systems can attain levels of reliability that allow support systems to drop the regulatory burdensome designation of "Engineered Safety Feature." Also, one goal of the IRIS project was to recede the emergency planning zone within the site exclusion area [Mai03] [Mai04]. Although not a current goal of the I ${ }^{2} S$-LWR project, it may be revisited with further $\mathrm{PDF}$ reductions.

5. Suggest critical deterministic analyses Although the Preliminary PRA shows clear advantages of an integral PCCS-PSS configuration, questions remain about the physical layout and thermal-hydraulic performance of such a design that require deterministic investigation. Additionally, significant analysis is warranted for NCGB phenomena, particularly at high points in primary DHRS heat exchangers, since they rank highly for multiple risk measures.

6. Estimate overall plant risk

With reemphasis that Preliminary PRA results are obviously preliminary and subject to large uncertainties, overall plant risk is encouragingly low. Several existing plant PRAs were first benchmarked, including AP1000, providing confidence to the safety team that Preliminary PRA results are reasonable [Wel14]. Table 6 compares the estimated base case I2S-LWR PDF with its own LERF goal, the stated AP1000 CDF, and the NRC overall CDF goal (including external events). Although PDF is already lower than project goals for CDF and LERF, the Preliminary PRA has provided additional insights anticipated to improve overall plant risk further.

Table 6: Comparison of damage frequency estimates (/ry).

\begin{tabular}{|c|c|c|c|}
\hline $\begin{array}{c}\text { NRC } \\
\text { CDF Goal }\end{array}$ & $\begin{array}{c}\text { AP1000 } \\
\text { CDF }\end{array}$ & $\begin{array}{l}\text { I'S-LWR }^{2} \text { LERF Goal }\end{array}$ & $\begin{array}{l}I^{2} S-L W R \\
\text { PDF }\end{array}$ \\
\hline $\begin{array}{c}1 \times 10^{-4} \\
{[\mathrm{NRCO} 4]}\end{array}$ & $\begin{array}{l}2.41 \times 10^{-7} \\
{[\text { WECO3] }}\end{array}$ & $3 \times 10^{-8}$ & $1.01 \times 10^{-8}$ \\
\hline
\end{tabular}


These encouraging estimates indicate that eliminating or minimizing initiating events, maximizing passivity, and balancing redundancy, diversity, and simplicity are effective approaches, rendering $\mathrm{I}^{2} \mathrm{~S}-\mathrm{LWR}$ inherently safe. Thus, Preliminary PRA has demonstrated tremendous utility in the early design process, helping the $\mathrm{I}^{2} \mathrm{~S}-\mathrm{LWR}$ project achieve its goal of unprecedented safety for an economically competitive gigawatt-scale reactor plant.

\section{Future Work}

The Preliminary PRA has successfully evaluated a key design alternative from a risk perspective, offering useful insights and decisive conclusions that would be otherwise obscured. Simultaneously, results also direct future work for the design, deterministic, and PRA teams. Several deterministic analyses were suggested in Section 5. For both design and PRA teams, two major issues arose: MCHX rupture and DVI line design.

The current PRA analysis shows that MCHX ruptures constitute about $40 \%$ of overall PDF. Although one may be tempted to interpret these results as an indictment on the MCHX design, examination of the absolute PDF values indicates that core damage risk has been minimized to such an extent that traditionally rare containment bypass events are comparable in frequency. However, until further data gathering is performed for these novel heat exchangers, especially in a nuclear environment, the Preliminary PRA team will undertake a parametric study to quantify overall plant risk should MCHX rupture frequency be shown to be lower, as expected.

Unlike MCHX ruptures, where redesign is not feasible at this point, several options for DVI lines still exist. The current design sought to minimize the number of vessel penetrations and balance penetration height between minimum RCS level and PCRS performance considerations. In minimizing vessel penetrations, each DVI line serves one accumulator, one PSS, and PCRS train. However, Table 3 and Assumption 1-5 illustrate the resulting vulnerability to common cause DVI line ruptures. Since the Preliminary PRA also suggests risks of SBLOCAs at higher penetration locations are minimal, connection of accumulators at separate, higher locations should be evaluated.

Other smaller vulnerabilities were identified during Preliminary PRA development and will be evaluated using trade-off, parametric, cut set and sensitivity studies.

The Preliminary PRA will continue to demonstrate that the I2S-LWR concept is not just a novel design that can be shown to be safe, but rather a novel reactor plant designed for safety from initial development. The integrated, iterative process amongst design, deterministic accident analyses, and probabilistic risk assessment ensures safety is never sacrificed for performance or vice versa. It is this cooperative design process that imbues our integral light-water reactor with its nucleus: inherent safety.

\section{Additions During Review}

Since original submission of this paper, uncertainty quantification has commenced, although it is not presented here since several key events, namely human failures and the 'borrowed' system probabilities, contain no uncertainty information at this stage.

Additionally, a final goal alluded to above is the development of strategies for increasing the transparency and auditability of complex PRAs using simplified, multi-path event trees (SMPETs) [McC16]. Improved PRA transparency is needed for increased auditability during licensing and troubleshooting. SMPETs show particular promise in highlighting key PRA insights during plant development, such as with

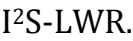

\section{Acknowledgements}

This research is being performed using funding received from the Department of Energy Office of Nuclear Energy's Nuclear Energy University Programs.

\section{References}

[AEC71] "General Design Criteria for Nuclear Power Plants," Title 10, Code of Federal Regulations, Part 50, Appendix A, U.S. Atomic Energy Commission (1971).

[ASM09] "Standard for Level 1/ Large Early Release Frequency Probabilistic Risk Assessment for Nuclear Plant Applications," ASME/ANS RA-Sa-2009, Part 2, Section 2-2, American Society of Mechanical Engineers (2009).

[EPR90] "Advanced Light Water Reactor Utility Requirements Document," Volume III, Chapter 1, Appendix A, Annex A, Electric Power Research Institute (1990).

[IAE91] "Safety related terms for advanced nuclear plants," IAEA-TECDOC-626, International Atomic Energy Agency (1991).

[Lee11] J.C. Lee and N.J. McCormick, Risk and Safety Analysis of Nuclear Systems, Wiley (2011). 
[Mai03] A. Maioli, "Risk-Informed Approach to the Design Phase of the IRIS Reactor," M.S. Thesis, Politecnico Di Milano (2003).

[Mai04] A. Maioli, D.J. Finnicum, Y. Kumagai, "IRIS Simplified LERF Model," Americas Nuclear Energy Symposium (2004).

[McC16] K.R. McCarroll, J.C. Lee, "A Simplified Multi-Path Event Tree for the Integral, Inherently-Safe Light Water Reactor (I'2S-LWR)," ANS Winter Meeting, Las Vegas, NV, November 6-10 (2016).

[Miz02] Y.O. Mizuno, K. Ogura, H. Ninokata, L.E. Conway, "Preliminary PSA of the IRIS Plant," $10^{\text {th }}$ International Conference on Nuclear Energy, Arlington, VA, April 1418, (2002).

[Mos98] A. Mosleh, D.M. Rasmuson, F.M. Marshall, "Guidelines on Modeling Common-Cause Failures in Probabilistic Risk Assessment," NUREG/CR-5485, U.S. Nuclear Regulatory Commission (1998).

[NRC83] "PRA Procedures Guide: A Guide to the Performance of Probabilistic Risk Assessments for Nuclear Power Plants," NUREG/CR-2300, Vol. 1, U.S. Nuclear Regulatory Commission (1983).

[NRC87] "Analysis of Core Damage Frequency From Internal Events: Methodology Guidelines, " NUREG/CR4550, Vol. 1, U.S. Nuclear Regulatory Commission (1987).

[NRC90] "Severe Accident Risks: An Assessment for Five U.S. Nuclear Power Plants," NUREG/CR-1150, U.S. Nuclear Regulatory Commission (1990).

[NRC04] "Regulatory Analysis Guidelines of the U.S. Nuclear Regulatory Commission," NUREG/BR-0058, U.S. Nuclear Regulatory Commission, (2004).

[NRC07a] "Standard Review Plan for the Review of Safety Analysis Reports for Nuclear Power Plants: LWR Edition - Transient and Accident Analysis," NUREG/CR0800, Chapter 15, U.S. Nuclear Regulatory Commission, (2007).

[NRC07b] "Industry-Average Performance for Components and Initiating Events at U.S. Commercial Nuclear Power Plants," NUREG/CR-6928, U.S. Nuclear Regulatory Commission, (2007).
[Per84] C. Perrow, "Normal Accidents: Living With HighRisk Technologies," Basic Books (1984).

[Pet12] B. Petrovic et al., "Integral Inherently Safe Light Water Reactor: A Proposal for an Integrated Research Project," NEUP-002-12 (2012).

[Smi11] C.L. Smith, S.T. Wood, "Systems Analysis Programs for Hands-On Integrated Reliability Evaluations (SAPHIRE) Version 8," NUREG/CR-7039 vol. 2, U.S. Nuclear Regulatory Commission (2011).

[WEC03] "AP1000 Design Control Document," APP-GWGL-022, Ch. 19, rev. 8, Westinghouse Electric Company (2003).

[Wel14] E. Welch, A. Manera, M. Memmott, P. Ferroni, M. Wang, J. C. Lee, "Preliminary Safety Considerations for the Integral Inherently Safe Light Water Reactor $\left(I^{2} S-\right.$ LWR)," Trans. Am. Nucl. Soc. 111, 961 (2014). 